\title{
Prevalences of endoscopic and histological findings in subjects with and without dyspepsia
}

\author{
Roar Johnsen, Bjørn Bernersen, Bøørn Straume, Olav Helge Førde, Leif Bostad, Per G Burhol
}

\begin{abstract}
Objective-To examine the association between dyspeptic symptoms and endoscopic and histological diagnoses.

Design-Cross sectional study of people with dyspepsia and controls matched for age and sex identified by questionnaire survey of all inhabitants aged 20 to 69. Endoscopy and histological examination was performed with the examiner blind to whether or not the patient had dyspepsia.
\end{abstract}

Setting-Population based survey in Sørreisa, Norway.

Subjects-All people with dyspepsia and age and sex matched people without dyspepsia were offered endoscopy. A total of 309 people with dyspepsia and 310 without dyspepsia underwent endoscopy, giving 273 matched pairs.

Main outcome measures-Prevalences of endoscopic and histological diagnoses made according to internationally accepted standards.

Results-In all, 1802 of $2027(88.9 \%)$ people returned the questionnaire. Of the 163 subjects who refused endoscopy, 114 were controls. Of five endoscopic and four histological diagnoses only peptic ulcer disease, endoscopic duodenitis, and active chronic gastritis were diagnosed significantly more often in people with dyspepsia. In all, $30 \%$ to $50 \%$ of the diagnoses of mucosal inflammation and peptic ulcer disease were made among subjects without dyspepsia, and only $10 \%$ of both those with and those without dyspepsia had normal endoscopic findings.

Conclusions-The diagnostic findings, with possible exceptions of peptic ulcer disease and endoscopic duodenitis, showed no association of clinical value with dyspeptic symptoms. The small number of "normal" endoscopic findings in both those with and those without dyspepsia challenge well accepted endoscopic and histological diagnostic criteria with relation to the upper gastrointestinal tract.

University of Troms $\varnothing$, 9000 Troms $\varnothing$, Norway Roar Johnsen, MD, research fellow in general practice Bjørn Bernersen, MD, research fellow in gastroenterology

Bjørn Straume, MD, assistant professor in epidemiology Olav Helge Førde, MD, professor in health services research

Leif Bostad, MD, consultant pathologist

Per G Burhol, MD, professor in gastroenterology

Correspondence to: Dr Johnsen.

BMf 1991;302:749-52

\section{Introduction}

The disability, suffering, and health care resources associated with patients in whom disease is wrongly suspected represent a mounting burden in modern medicine and permanently challenge our ability to recognise normality and discriminate between disease and "non-disease."

In gastroenterology the controversy around the "dyspeptic myth" of gastroduodenitis is one of many examples of this problem.' So far the discussion on gastroduodenitis has mainly focused on the association with dyspepsia and peptic ulcer disease. ${ }^{1.7}$ Studies on the occurrence of this condition among people without dyspepsia, which could have settled parts of the controversy, have been scarce and based on small populations. ${ }^{89}$ The lack of agreement on which symptoms should be included in the term "dyspepsia" may likewise have nourished the controversy.

A working party of gastroenterologists defined dyspepsia as any symptom "considered to be referable to the proximal alimentary tract," restricted the term to "chronic or recurrent abdominal pain or nausea, or abdominal symptoms, often related to feeding." 11 Any population of people with dyspepsia selected according to these definitions could vary considerably regarding both the character of single symptoms and that of complexes of symptoms.

Most studies of patient populations with different prevalences of peptic ulcer disease are inconclusive regarding the relation between chronic gastritis and dyspepsia and peptic ulcer disease. The few population studies on chronic gastritis reject any association with dyspepsia and question an association with peptic ulcer disease. ${ }^{12}{ }^{13}$ Corresponding surveys on duodenitis are not available, and the discussion on whether endoscopic and histological duodenitis represents the same disorder and is part of the range of peptic ulcer disease is based on patient surveys and a few studies in healthy volunteers. ${ }^{1.589}$

A discussion on normality and the clinical value of dyspeptic symptoms associated with differen conditions in the upper gastrointestinal tract can be assessed only from population based studies. Despite common agreement on the diagnostic criteria of the stages of different pathological conditions in the upper gastrointestinal tract, ${ }^{44-17}$ a main problem in all open studies is the observer bias related to the knowledge of whether or not the patient has symptoms. To achieve a non-biased assessment of the clinical value of dyspeptic symptoms we performed endoscopy in subjects with and without dyspeptic symptoms, with the examiner being unaware of whether or not the subjects had symptoms.

\section{Methods}

After a population based questionnaire survey of all inhabitants aged 20-69 years in the municipality of Sørreisa in northern Norway $(n=2027)^{18}$ all subjects reporting dyspepsia and matched subjects without dyspepsia were offered endoscopy of the upper gastrointestinal tract. There was no financial gain or hint of health benefits associated with the invitation. The subjects with dyspepsia were selected on the basis of answers to the first two or the last, or both, of the three questions: "Have you ever had abdominal pain of at least two weeks' duration?"; "If yes, was the pain located to the upper abdomen?"; and "Have you ever had heartburn or acid regurgitation almost daily during at least one week?"

Subjects with dyspepsia who reported a history of peptic ulcer, abdominal surgery, gall stones, kidney stones, or cardiac disease were excluded. For each 
subject with dyspepsia a corresponding control subject without dyspepsia, matched for sex and age within the same 10 year age group, was randomly selected and offered endoscopy. Thus 782 subjects were invited for endoscopy, and 309 subjects with dyspepsia and 310 controls attended $(79 \cdot 2 \%)$, giving 273 matched pairs. Details of methods are given elsewhere. ${ }^{18}$ All endoscopies were performed by one of us (BB), who is a trained endoscopist and who was blinded with regard to whether he was examining a subject with dyspepsia or a control subject. Endoscopic findings were classified according to the criteria described by Savary and Miller (for oesophagitis), ${ }^{19}$ Johnsson et al (for hiatus hernia), ${ }^{20}$ Myren and Serck-Hanssen (for endoscopic gastritis and gastroduodenal reflux), ${ }^{21}$ Venables (for duodenitis), ${ }^{17}$ and Bernersen et al (for peptic ulcer and deformed duodenal bulb). ${ }^{18}$ Peptic ulcer disease was defined as having an active peptic ulcer or a deformed duodenal bulb.

Biopsy specimens were obtained from the corpus and antral part of the stomach, including both the greater and lesser curvatures; from the proximal and distal parts of the duodenum; and from all visible lesions. The specimens for morphological examination were prepared according to standard methods and interpreted blindly by an experienced pathologist (LB). Inflammation of gastric and duodenal mucosa was classified according to Whitehead et $a l^{1 / 15}$ and Owen. ${ }^{22}$ The study was approved by the regional committee of medical research ethics.

Statistics-Differences in overall prevalences were examined by the $\chi^{2}$ test and by McNemar's test in the paired analysis. Age trends, overall and within sexes, were evaluated by $t$ test of the regression coefficients in simple linear regression. ${ }^{23}$ All prevalences of various symptoms were adjusted for age and sex in a covariance analysis. $^{24}$

\section{Results}

Some 1802 of 2027 (88.9\%) subjects returned the questionnaire. Of the 163 subjects who refused endoscopy, 114 were controls. There were no significant differences in the sex distribution between responders and non-responders and between subjects who had endoscopy and those who refused endoscopy. Compared with the total population middle aged men and women were slightly overrepresented among those who had endoscopy. Women who did not respond to the questionnaire or who refused endoscopy were significantly younger compared with the total population. ${ }^{18}$

Figures 1 and 2 present the sex and age specific frequencies of various endoscopic and histological diagnoses and the proportion of subjects with normal mucosa in their biopsy specimens for 339 men and 280

TABLE I-Prevalences of endoscopic and histological findings in 273 subjects with dyspepsia and 273 sex and age matched controls in Sorreisa, Norway, in 1987. Figures are numbers (percentages)

Subjects with dyspepsia Controls Discordant pairs ${ }^{\star}$ Significance $f(p$ Value)

Oesophagitis (grade I or II
Hiatus hernia
Superficial gastritis
Atrophic gastritis
Duodenogastric reflux
Peptic ulcer disease
Duodenitis
Normal endoscopy

Chronic superficial gastritis

Chronic atrophic gastritis Chronic atrop
(all types) Active chronic gastritis Duodenitis

Normal histology

Normal endoscopy/histology

\section{Endoscopic diagnosis}

$33(12 \cdot 1)$
$9(3 \cdot 3)$

$55(20 \cdot 1)$

$10(3 \cdot 7)$

$50(18 \cdot 3)$

$23(8 \cdot 4)$

$\begin{array}{rr}23(20 \cdot 1) & 24(8 \cdot 8) \\ 146(53 \cdot 5) & 181(66 \cdot 3)\end{array}$

Histological diagnosis

$\begin{array}{cc}\text { Histological diagnosis } \\ 118(43 \cdot 2) & 102(37 \cdot 4)\end{array}$

$170(62 \cdot 3)$

$73(26 \cdot 7)$

$170(62 \cdot 3)$
$43(15 \cdot 8)$

$43(15 \cdot 8)$
$28(10 \cdot 3)$

\section{$22(8 \cdot 1)$}

$7(2 \cdot 6)$

$44(16 \cdot 1)$
$11(4 \cdot 0)$

$138(50 \cdot 5)$

$52(19 \cdot 0)$
$191(70 \cdot 0)$

$191(70 \cdot 0)$
$35(12 \cdot 8)$

$35(12 \cdot 8)$
$31(11 \cdot 4)$
$31 / 20 \quad 0 \cdot 26$

$48 / 37$

$10 / 11$
$41 / 26$

$22 / 9$

$52 / 21$
$47 / 82$

$63 / 47$
$81 / 49$

$58 / 37$

$38 / 59$

$37 / 29$
$26 / 29$
$0 \cdot 26$
$0 \cdot 79$

$0 \cdot 28$

$1 \cdot 0$

0.09

$0 \cdot 02$

0.0005
0.003

$0 \cdot 15$

$0 \cdot 007$

0.04

$0 \cdot 04$

$0 \cdot 4$

0.8
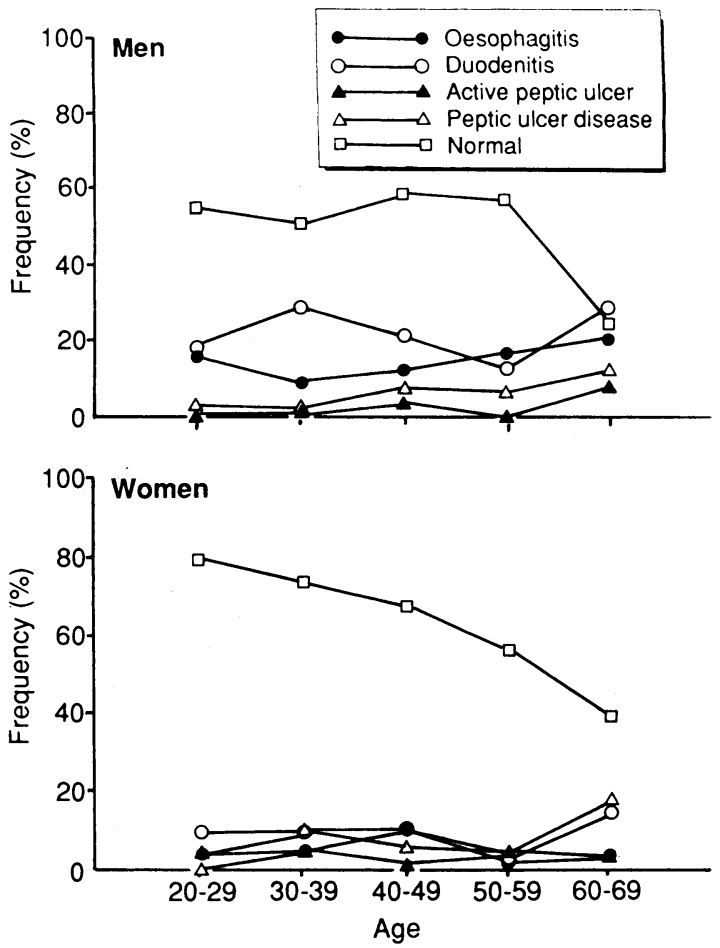

FIG 1-Frequency of endoscopic findings by age and sex among 339 men and 280 women in Sorreisa, Norway, in 1987
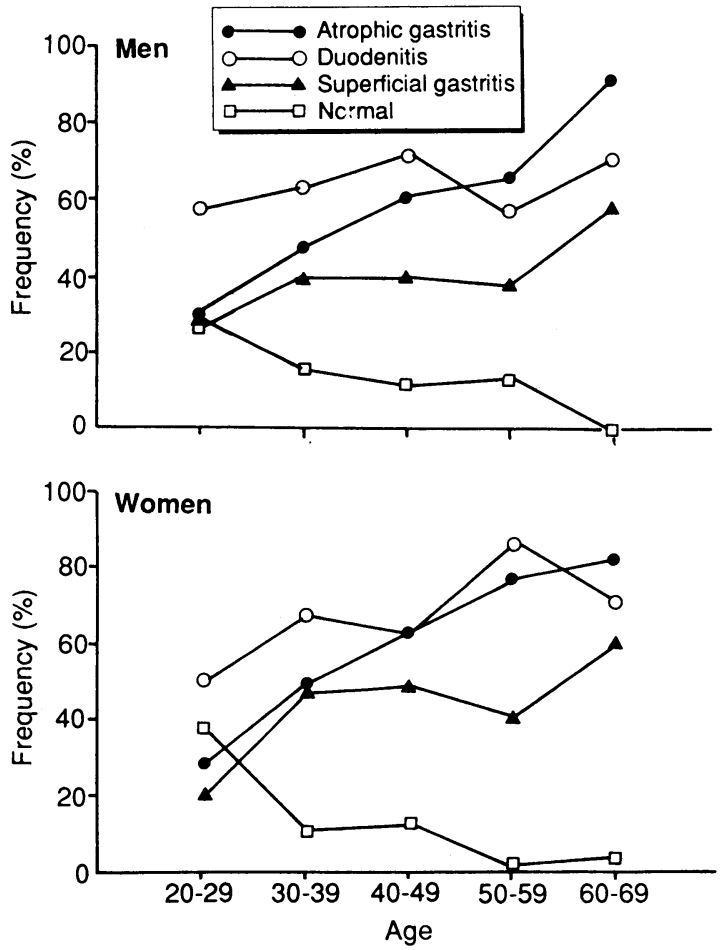

FIG 2-Frequency of histological findings by age and sex among 339 men and 280 women in Sørreisa, Norway, in 1987

women. The data for subjects with dyspepsia and controls were pooled as the age and sex distributions of the various diagnoses were generally equal in both groups. The age adjusted frequencies of oesophagitis found on endoscopy were $13 \cdot 3 \%$ in men and $5 \cdot 8 \%$ in women $(p=0.002)$, and the corresponding figures for duodenitis were $22.8 \%$ and $5.9 \%(p=0.0001)$ and for peptic ulcer disease were $5 \cdot 1 \%$ and $7 \cdot 9 \%(p=0 \cdot 3)$ (fig $1)$. The frequencies of all types of gastritis found on histological examination in both sexes and duodenitis in women showed a significant age trend but no significant sex differences (fig 2). No significant differences in age trends between sexes were found for any of the diagnoses.

Table I gives the paired analysis of the prevalences of 


\begin{tabular}{|c|c|c|c|c|}
\hline \multirow[b]{2}{*}{ Diagnosis } & \multicolumn{3}{|c|}{ Subjects with dyspepsia } & \multirow[b]{2}{*}{ Controls $(n=310)$} \\
\hline & Epigastric pain $(n=64)$ & Heartburn $(n=142)$ & $\begin{array}{l}\text { Both epigastric pain and } \\
\text { heartburn }(n=61)\end{array}$ & \\
\hline \multicolumn{5}{|c|}{ Endoscopic diagnosis } \\
\hline Oesophagitis (grade I or II) & $10(15.8)[7.8$ to $26 \cdot 9]$ & $15(10 \cdot 5)[6 \cdot 1$ to $17 \cdot 1]$ & $7(11 \cdot 5)\{4 \cdot 7$ to $22 \cdot 2]$ & $25(9 \cdot 0)[5 \cdot 5$ to $12 \cdot 1]$ \\
\hline Peptic ulcer disease & $3(3.8)[1.0$ to 13.1$]$ & $13(9 \cdot 8)[5 \cdot 1$ to $15 \cdot 4]$ & $8(12 \cdot 4)[5 \cdot 8$ to $24 \cdot 2]$ & $12(3 \cdot 8)[2 \cdot 1$ to $6 \cdot 9]$ \\
\hline Duodenitis & $9(14 \cdot 2)[6 \cdot 6$ to $25 \cdot 0]$ & $33(22 \cdot 9)[16 \cdot 9$ to $31 \cdot 5]$ & $19(31 \cdot 5)[19 \cdot 9$ to $44 \cdot 3]$ & $30(9 \cdot 7)[6 \cdot 6$ to $13 \cdot 6]$ \\
\hline \multicolumn{5}{|c|}{ Histological diagnosis } \\
\hline Superficial gastritis & $33(49 \cdot 1)[38 \cdot 7$ to $64 \cdot 3]$ & $63(46 \cdot 2)[36 \cdot 7$ to $53 \cdot 1]$ & $24(37 \cdot 4)[27 \cdot 1$ to $52 \cdot 7]$ & $117(37 \cdot 6)[34 \cdot 4$ to $45 \cdot 7]$ \\
\hline Chronic atrophic gastritis (all types) & $45(65 \cdot 4)[57 \cdot 6$ to $81 \cdot 1]$ & $87(64.9)[52.8$ to $69 \cdot 5]$ & $35(53 \cdot 5)[44 \cdot 1$ to $70 \cdot 0]$ & $152(48 \cdot 7)[44 \cdot 2$ to $55 \cdot 8]$ \\
\hline Active chronic gastritis & $26(39 \cdot 3)[28 \cdot 5$ to $53 \cdot 6]$ & $30(22 \cdot 2)[15 \cdot 0$ to $29 \cdot 2]$ & $14(21 \cdot 8)[13 \cdot 2$ to $35 \cdot 5]$ & $55(17 \cdot 6)[14 \cdot 1$ to $23 \cdot 2]$ \\
\hline Duodenitis & $44(67.5)[55.9$ to 80.0$]$ & $81(57 \cdot 0)[49 \cdot 2$ to $66 \cdot 1]$ & $43(69 \cdot 5)[57 \cdot 4$ to $81 \cdot 5]$ & $212(68 \cdot 3)[64 \cdot 5$ to $75 \cdot 1]$ \\
\hline
\end{tabular}

diagnoses based on endoscopic and histological findings in the 273 matched pairs of subjects. The only highly significant differences between subjects with dyspepsia and controls were found in subjects with duodenitis on endoscopy $(p=0.0005)$ and those with histological findings of chronic atrophic gastritis $(p=0 \cdot 007)$. When subjects with active chronic gastritis were excluded from the analysis the difference between subjects with dyspepsia and controls with respect to histological findings indicating chronic gastritis became insignifcant. In fact, $50 \%$ of controls had atrophic gastritis. More controls than subjects with dyspepsia had duodenitis on histological examination. The figures for duodenitis grade II (increased cellularity of the lamina propria and abnormality of the surface epithelium) were $20 \cdot 1 \%$ in subjects with dyspepsia and $24 \cdot 2 \%$ in controls.

Of the 309 subjects with dyspepsia, $125(40 \cdot 5 \%)$ reported having epigastric pain, of whom $64(51 \cdot 2 \%)$ reported having no simultaneous heartburn, and $245(79 \cdot 3 \%)$ reported having heartburn or acid regurgitation. Forty two $(17 \%)$ of those with heartburn or acid regurgitation had abdominal pain that was not in the epigastric region, $142(58 \%)$ had heartburn without abdominal pain, and $61(24.9 \%)$ had both heartburn and epigastric pain.

Table II gives the age and sex adjusted prevalences of the endoscopic and histological findings; the dyspeptic subjects are grouped according to reported symptom. (The 42 subjects with abdominal pain other than epigastric pain were omitted from this analysis.) All diagnoses based on endoscopy showed the highest point estimates among those with both epigastric pain and heartburn, except for oesophagitis, which was at its highest prevalence in the subjects with epigastric pain. The prevalences of peptic ulcer disease and duodenitis were higher among those with heartburn than among those with only abdominal pain, though the confidence intervals overlapped. The prevalences of all gastritis found on histological examination were, on the contrary, highest in the group with epigastric pain. The confidence intervals were, however, wide in all three symptom groups, showing the loss of statistical power due to small numbers.

\section{Discussion}

This study was based on a population survey with a high rate of response $(88.9 \%)$ and was designed to explore the associations between dyspeptic symptoms and endoscopic findings by comparing the findings in subjects with dyspepsia and those in matched controls. To minimise observer bias both the endoscopist and the pathologist were unaware whether or not the subjects had symptoms of dyspepsia, and the pathologist had no information on the endoscopic findings.

Our main observation was that $30 \%$ to $50 \%$ of the cases of gastroduodenal inflammation and peptic ulcer disease were diagnosed among control subjects and that only $10 \%$ of controls were without any endoscopic or histological diagnoses. The considerable overlap of diagnoses of inflammation between subjects with and subjects without dyspepsia may support, with reservations because of our cross sectional design, the Spiro's hypothesis that mucosal inflammation is a continuum, with peptic ulcer disease as a stage in the process. ${ }^{25}$ The relation, if any, between the inflammatory process and dyspeptic symptoms is, however, obscure.

Multiple methodological problems are inherent in this kind of study. Besides the observer bias problem, special care should be devoted to selecting the population to be examined. Compared with subjects in population based surveys hospital patients are highly selected regarding age, seriousness of symptoms, and disease. Furthermore, the expected frequencies of endoscopic findings could depend, as shown in this study, on which dyspeptic symptoms the selection of the population is based. For comparative purposes the wide definition of dyspepsia seems unsuitable.

\section{ASSOCIATION BETWEEN DYSPEPSIA AND DIAGNOSES}

The association between dyspepsia and peptic ulcer disease is well documented and accepted, although peptic ulcers that do not cause dyspepsia are prevalent. ${ }^{91826}$ Endoscopic duodenitis, which displays the same clinical picture as peptic ulcer disease, is also associated with dyspepsia, either as a part of the range of peptic ulcer disease $e^{1728}$ or as a clinical entity of its own. ${ }^{17} 29$ Although the associations between dyspepsia and peptic ulcer disease and dyspepsia and endoscopic duodenitis were confirmed in the present study, 30\% of the subjects with these diagnoses did not have dyspepsia.

The association between chronic gastritis and dyspeptic symptoms, on the other hand, is disputed by many authors, ${ }^{1316}$ though Earlam et al and Joffe and Rao claim that corpus and antral gastritis could cause symptoms. ${ }^{30} 31$ We found that active chronic gastritis was significantly commoner among subjects with dyspepsia, but gastritis was diagnosed in more than $50 \%$ of the controls, and more than $40 \%$ of the cases of gastritis, with or without activity, were diagnosed among people without dyspepsia. Neither grade I nor grade II histologically classified duodenitis was associated with dyspepsia. In fact, the point estimate for duodenitis was higher among controls than among people with dyspepsia.

\section{NON-DISEASE IN UPPER GASTROINTESTINAL TRACT}

Endoscopic examination of subjects with dyspepsia, supplemented with histological diagnosis, has shown that few subjects (12-25\%) have a "normal" upper gastrointestinal tract. ${ }^{89} 12303233$ Two of the studies were, however, concerned only with gastritis. ${ }^{32}{ }^{33}$ In our study the subjects with normal findings were surprisingly few. Some of the endoscopic diagnoses, such as gastritis, duodenogastric reflux, and hiatus hernia, may be considered non-pathological conditions and such results classified as normal. Still, the high 
frequency of abnormalities on histological examination would mean that few subjects had a normal mucosa.

The clinical value of pathological findings depends on their ability to classify subjects with common features - for example, having symptoms - or to give information on prognosis. The endoscopic findings in our study, with the possible exceptions of peptic ulcer disease and endoscopic duodenitis, showed no association with dyspeptic symptoms that was of clinical value. This corresponds well with the results of therapeutic trials that show a beneficial effect both on symptoms and peptic ulcer disease and endoscopic duodenitis ${ }^{29}$.4 $^{4}$ whereas convincing evidence of a therapeutic effect on other mucosal inflammations is lacking. In the population the degree of mucosal inflammation apparently represents various degrees in an inflammatory process rather than separate diagnostic entities. Traditionally, clinicians have used as a cut off point between no disease and disease the presence of an ulcer in the mucosa. The ulceration process must, however, have an initial stage at which the ulcer is invisible through the endoscope. ${ }^{25}$ The location, distribution, and severity of the inflammation might contribute when considering alternative cut off points. In the paired analysis we found no association between symptoms and isolated inflammation in the corpus, antrum, proximal, or distal duodenum. Location and distribution of the inflammation therefore had poor discriminatory power in this study. Although Toukan et al have shown that a high neutrophilic cell count could discriminate between symptom causing gastritis and inflammation not causing dyspepsia, ${ }^{35}$ we think that the only rational basis for therapeutic considerations is the symptoms, and not endoscopically or histologically diagnosed inflammation of a mild to moderate degree.

The surprisingly high frequency of positive diagnoses in our study cannot be explained by use of odd provincial diagnostic criteria: both endoscopy and histological examination were performed according to internationally accepted and diagnostic standards of widespread use. When, despite this, the proportion of normal findings on standard endoscopy amounts to a modest $10 \%$ it reflects the use of a normative concept of normality, where the norm is the non-prevalent, noninflamed gastrointestinal mucosa. Our findings challenge both endoscopists and pathologists to search for new distinctions between disease and non-disease.

1 Thomson WO, Joffe SN, Robertsen AG, Lee FD, Imrie CW, Blumgart LH. Is duodenitis a dyspeptic myth? Lancet $1977 ; \mathrm{i}: 1197-8$.

2 Anonymous. Duodenitis-any progress? Lancet 1985; ;i: $1222-3$

Cheli R. Symptoms in chronic non-specific duodenitis. Scand $\mathcal{F}$ Gastroenterol 1982;17 (suppl 79):84-6.

4 Joffe SN. Relevance of duodenitis to non-ulcer dyspepsia and peptic ulceration. Scand f Gastroenterol 1982;17 (suppl 79):88-97.

5 DeLuca VA, Winnan GG, Sheahan DG, et al. Is gastroduodenitis part of peptic ulcer disease? f Clin Gastroenterol 1981;3 (suppl 2):17-22.

peptic ulcer disease? 7 Clin Gastroenterol $981 ; 3$ (supp 2):17-22.
6 Talley JN, Phillips SF. Non-ulcer dyspepsia: potential causes and pathophysiology. Ann Intern Med 1988;108:865-79.
phey

7 Guslandi M. Focus on duodenitis. Dig Dis Sci 1986;4:231-9.

8 Kreunig J, Bosman FT, Kuiper G, Van Der Wal AM, Lindman J. Gastric and duodenal mucosa in "healthy" individuals. $\mathcal{F}$ Clin Pathol 1978;31:69-77.

9 Akdamar K, Ertan A; grawal NM, McMahon FG, Ryan J. Upper gastrointestinal endoscopy in normal asymptomatic volunteers. Gastrointestinal Endoscopy 1986;32:78-80.

10 Colin-Jones DG. Management of dyspepsia: report of a working party. Lancel 1988;i:576-9.

11 Barbara L, Camilleri M, Corinaldesi R, et al. Definition and investigation of dyspepsia. Consensus of an international ad hoc working party. Dig Dis $\mathrm{Sc}_{\mathrm{c}}$ 1989;34:1272-6.

12 Siurla $M$, Varis $K$, Kekki $K$. New aspects on epidemiology, genetics and dynamics of chronic gastritis. Frontiers of (jastrointestinal Research 1980;6: $148-66$.

13 Villako $\mathbf{K}$, Ihamaeki T, Tamm A, Tammur R. Upper abdominal complaints and gastritis. Ann Clin Res 1984;16:192-4.

14 Whitehead R, Truelove SC, Gear MWL. The histological diagnosis of chronic atritis in fibreoptic gastroscope hiopsy specimens. $f$ Clin Pathol 1972; 25:1-11.

15 Whitehead R, Roca M, Meikle DD, Skinner J, Truelove SC. The histological classification of duodenitis in fibrotic biopsy specimens. Digestion 1975;13: 29-36.

16 Cheli R, Perasso A, Giacosa A. Dyspepsia and chronic gastritis. Hepatogastroenterologv 1983;30:21-3

17 Venables CW. Duodenitis. Scand F Gastroenterol 1985;20 (suppl 109):91-7

8 Bernersen B, Johnsen R, Straume B, Burhol PG, Jenssen TG, Stakkevold PA. Towards a "true" prevalence of peptic ulcer. Gut 1990;31:989-92.

19 Savary M, Miller G. Der Oesophagus. Lehrbuch und endoskopischer Atlas. Solothurn: Gassmann, 1977

20 Johnsson F, Joelsson B, Gudmundsson K, Greiff L. Symptoms and endoscopic findings in the diagnosis of gastroesophageal reflux disease. Scand $f$ Gastroenterol 1987:22:714-8.

21 Myren J, Serck-Hanssen A. The gastroscopic diagnosis of gastritis. Scand $\mathcal{f}$ Gastroenterol 1974;9:457-62.

22 Owen DA. The diagnosis and signficance of gastritis. Pathology Annual 1979;1:247-71.

23 Snedecor GW, Cochran WG. Statistical methods 6th ed. Iowa: Iowa State University Press, 1967:432-8.

24 Nie HH, Hull CH, Jenkins JG, Steinbrenner K, Bent DH. Statistical package for the social sciences. 2nd ed. New York: McGraw Hill, 1975.

25 Spiro HM. Visceral viewpoints. Moynihan's disease? The diagnosis of duodenal ulcer. N Engl f Med 1974;291:567-9.

26 Jorde R, Bostad L, Burhol PG. Asymptomatic gastric ulcer: a follow-up study in patients with previous gastric ulcer disease. Lancet 1986;i:119-21.

27 Greenlaw R, Sheahann DG, DeLuce V, Miller D, Myerson D, Myersom P. Gastroduodenitis: a broader concept of peptic ulcer disease. Dig Dis Sci $1980 ; 25: 660-72$

28 Sircus W. A clinical, endoscopic and histopathologic study. $Q \mathcal{J}$ Med 1985;56:593-600.

29 Danielsson A, Ek B, Nyhlin H, Steen L. The relationship between active peptic ulcer, endoscopic duodenitis and symptomatic state after treatment peptic ulcer, endoscopic duodenitis and sym
with cimetidine. Ann Clin Res 1980;12:4-12.

30 Earlam RJ, Amerigo J, Kakavoulis T, Pollack DJ. Histological appearances of oesophagus, antrum and duodenum and their correlation with symptoms in patients with a duodenal ulcer. Gut 1985;26:95-100.

31 Joffe SN, Rao SS. Symptoms of gastritis. Scand F Gastroenterol 1982;17 (suppl 79): $62-5$

32 Cheli R, Giacosa A. Duodenal ulcer and chronic gastritis. Endoscopy 1986;18:125-6.

33 Villako K, Tamm A, Savisaar E, Ruttas $M$. Prevalence of antral and fundic gastritis of an Estonian rural population. Scand J Gastroenterol 1976;ii:81722.

34 Mackinnon M, Willing RL, Whitehead R. Cimetidine in the management of symptomatic patients with duodenitis. Dig Dis $S_{c}$ 1 1982:27:217-9.

35 Toukan AU, Kamal MF, Amr SS, Arnaout MA, Abu-Romiyeh AS. Gastroduodenal inflammation in patients with non-ulcer dyspepsia. Dig Dis $S c i$ 1985;30:313-20.

(Accepted 7 fanuary 1991)

\section{Correction}

Is risk of Kaposi's sarcoma in AIDS patients in Britain increased if sexual partners came from United States or Africa?

Because of an editorial oversight the authors of this paper (Dr Valerie Beral and others; 16 March, p 624) did not see the abstract before it was published. There were several errors in the printed abstract, and the authors' corrected version is published below.

Objective-To determine whether the risk of Kaposi's sarcoma in patients with AIDS is increased by sexual contact with groups from abroad with a high incidence of Kaposi's sarcoma.

Design-Analysis of risk of Kaposi's sarcoma in patients with AIDS, according to country of origin of their sexual partners.

Setting-United Kingdom.

Patients -2830 patients with AIDS reported to the Communicable Disease Surveillance Centre and the Communicable Disease (Scotland) Unit up to March 1990, of whom 566 had Kaposi's sarcoma.

Main outcome measures-Percentage of patients with AIDS who had Kaposi's sarcoma.

Results -537 of 2291 homosexual or bisexual men $(23 \%)$ with AIDS had Kaposi's sarcoma; 10\% (14/135) of the men and women who acquired HIV by heterosexual contact had Kaposi's sarcoma. None of the 316 subjects who acquired HIV through non-sexual routes had Kaposi's sarcoma. Kaposi's sarcoma was more common among homosexual men whose likely source of infection included the United States (171/551, $31 \%)$ or Africa $(9 / 34,26 \%)$ than among those infected in the United Kingdom $(119 / 625,19 \%)(\mathbf{p}<0.05)$.

Conclusion-The data suggest that Kaposi's sarcoma is caused by a sexually transmissible agent which was introduced into the British homosexual population mainly from the United States. 